\title{
Serum Lactate and Acute Mesenteric Ischemia: An Observational, Controlled Multicenter Study
}

\section{Olivier Collange ( $\nabla$ olivier.collange@chru-strasbourg.fr )}

Hopitaux universitaires de Strasbourg https://orcid.org/0000-0003-4169-1517

\section{Marc LOPEZ}

Hopitaux universitaires de Strasbourg

Anne LEJAY

Hopitaux universitaires de Strasbourg

Patrick PESSAUX

Hopitaux universitaires de Strasbourg

\section{Alexandre OUATTARA}

CHU de Bordeaux: Centre Hospitalier Universitaire de Bordeaux

\section{Antoine DEWITTE}

$\mathrm{CHU}$ de Bordeaux: Centre Hospitalier Universitaire de Bordeaux

\section{Thomas RIMMELE}

Hospices Civils de Lyon

\section{Thibaut GIRARDOT}

Hospices Civils de Lyon

\section{Darko ARNAUDOVSKI}

APHP: Assistance Publique - Hopitaux de Paris

\section{Pascal AUGUSTIN}

APHP: Assistance Publique - Hopitaux de Paris

\section{Nabil CHAKFE}

Hopitaux universitaires de Strasbourg

\section{Charles TACQUARD}

Hopitaux universitaires de Strasbourg

\section{Walid OULEHRI}

Hopitaux universitaires de Strasbourg

\section{Laurent ZIELESKIEWICZ}

AP-HM: Assistance Publique Hopitaux de Marseille

\section{François SEVERAC}

Hopitaux universitaires de Strasbourg

\section{Marc LEONE}

AP-HM: Assistance Publique Hopitaux de Marseille 


\section{Research}

Keywords: intensive care, lactate, mesenteric vascular occlusion, multiple organ failure, diagnosis, prognosis.

Posted Date: June 11th, 2021

DOl: https://doi.org/10.21203/rs.3.rs-573044/v1

License: (c) (1) This work is licensed under a Creative Commons Attribution 4.0 International License. Read Full License 


\section{Abstract \\ Purpose}

Early diagnosis of acute mesenteric ischemia (AMI) is key to survival but remains extremely difficult, as the symptoms are vague and non-specific. Although international guidelines recommend that serum lactate is not used for AMI diagnosis, this parameter is still specifically taken into account for the diagnosis and prognosis of AMI. Our hypothesis was that serum lactate levels cannot be used to diagnose AMI or predict its outcome.

\section{Methods}

This was an ancillary, retrospective, observational, controlled multicenter study, approved by an Ethics Committee. Patients with AMI at adult intensive care unit (ICU) admission were included (AMI group) and matched to ICU patients without AMI (control group). Matching criteria were center, period, gender, age, and severity. Serum lactate levels were measured on day 0 (D0) and day 1 (D1) and the lactate difference (D0-D1) was calculated.

\section{Results}

Two hundred and seventy-four patients were included. Serum lactate levels were elevated in both groups at D0 and D1 but there was no significant difference between groups at D0 $(2.7[1.3 ; 5.5]$ vs $3.4[1.9 ; 6.1]$ $\mathrm{mmol} / \mathrm{L} ; \mathrm{p}=0.284)$, D1 $(1.8[1.2 ; 3.1]$ vs $2.4[1.5 ; 4.6] \mathrm{mmol} / \mathrm{L}, \mathrm{p}=0.547$; respectively for control and AMI groups) or D0-D1. Thus, the performance of serum lactate for AMI diagnosis was poor. Concerning AMI outcome, serum lactate levels predicted ICU death in both groups at D0 and D1.

\section{Conclusions}

no specific association was observed between serum lactate levels and AMI. Serum lactate should not be used for the diagnosis of AMI but may help assess disease severity.

\section{Take Home Message}

No specific link was observed between serum lactate levels and the diagnosis or outcome of AMI. There is still no useful diagnostic biomarker for AMI and normal serum lactate does not rule out this diagnosis. Once AMI has been diagnosed, serum lactate may be used to assess the overall severity of the patient and tailor its management.

\section{Introduction}


Acute mesenteric ischemia (AMI) has a hospital incidence of 7.3/100,000 patient-years, although it is thought to be under-reported [1]. AMI is estimated to account for one in 1,000 acute hospital admissions [2] and one in 100 patients with an acute abdomen [3]. The incidence of AMI increases exponentially with age and accounts for up to $10 \%$ of acute abdomen cases in patients aged over 70 years $[1,3]$. The incidence of AMI should therefore increase in future with the ageing of the population [4]. Short-term mortality in AMI still exceeds 50\% [5] and long-term mortality remains high in survivors of the acute phase of the disease [1].

Early diagnosis and prompt revascularization are key to survival [2]. However, early diagnosis remains extremely difficult, as the symptoms of AMI are vague and non-specific [6]. Serum lactate has been suggested as a useful biomarker for the diagnosis of AMI [7]. However, several studies have shown that serum lactate is a poor diagnostic marker for AMI [6-8]. The European Society of Vascular Surgery (ESVS) and the European Society for Trauma and Emergency Surgery (ESTES) underlined the lack of sensitivity and specificity of serum lactate and recommended that serum lactate should not be used for the diagnosis of AMI $[2,3]$. However, the level of evidence for this recommendation is low and many clinicians continue to rely on serum lactate to make the diagnosis of $\operatorname{AMI}[9,10]$. At the same time, several studies have suggested that serum lactate can be used to predict AMI outcome [11] [12]. Serum lactate is still considered to be associated with the diagnosis or prognosis of AMI. Our hypothesis was that in the intensive care unit (ICU), serum lactate levels cannot be specifically used for AMI diagnosis or to predict its outcome.

The aim of our study was to compare serum lactate levels in ICU patients with and without AMI. Our primary objective was to compare serum lactate levels in both groups. Our secondary objective was to compare the ability of serum lactate to predict ICU mortality in both groups.

\section{Method}

\section{Centers and authorization}

This was an ancillary, retrospective, observational, multicenter study conducted in four French academic ICUs (Strasbourg, Bordeaux, Lyon, Paris). The current study is ancillary to the largest published study on AMI to date, which included 780 patients [5]. This 780-patient cohort is referred to as the "MICCU cohort". In France, ICUs are organized according to the model described elsewhere [13]. The study was approved by the Ethics Committee of the French Society of Anesthesia and Intensive Care (IRB CERAR-00010254 -2016-070) in accordance with French regulations [14].

\section{Patients and matching process}

We compared ICU patients with and without AMI (AMI and control groups respectively).

Patients were enrolled from 4 centers of the MICCU cohort. Within the MICCU cohort, diagnosis of AMI required written reports of the computed tomography scan, gastrointestinal endoscopy or surgery [5] and 
AMI was diagnosed at ICU admission or during ICU stay. For this study, we selected patients from the MICCU cohort who were diagnosed with AMI within 24 hours of admission to the ICU. Then, for each AMI patient, we identified a control ICU patient without AMI (on admission or during ICU stay). AMI and control patients were matched by center, period (2008-2013), severity, age and gender. The Simplified Acute Physiology Score II (SAPS II) that predicts in-hospital mortality based on the collection of 17 variables at ICU admission $[15,16]$ was used to assess patient severity. Patients were matched by SAPS II category, as follows: $<15 ; 15-24 ; 25-34 ; 35-44 ; 45-54 ; 55-64 ; 65-74$ and $\geq 75$. Although age is one of the 17 variables of the SAPS II, we used this variable as a specific matching criterion. AMI incidence increases in elderly patients [1] and age is associated with a specific risk of mortality in ICU patients [17]. Patients were matched by age categories as follows: $<40 ; 40-59 ; 60-69 ; 70-74 ; 75-79 ; \geq 80$ years-old. Exact matching was performed manually.

\section{Chronology}

In both groups, day 0 (D0) was the first $24 \mathrm{~h}$ after ICU admission and day 1 (D1) was 24-48h after ICU admission.

\section{Collection of general parameters}

Data were retrospectively collected from electronic or paper records. We recorded the following data: age, gender, SAPS II, history of atrial fibrillation, peripheral arterial disease or cancer. The SAPS II score was calculated at D0. We recorded the admission type (medical, non-urgent surgical or urgent surgical) and the use of vasopressors (norepinephrine, epinephrine or dobutamine) at D0 and D1. The worst platelet count, the need for renal replacement therapy (RRT) and the presence of liver failure (defined as a prothrombin time ratio $<50 \%$ ) were recorded at D1.

The sequential organ failure assessment (SOFA) score was calculated at D0 [18]. Duration of mechanical ventilation, ICU length of stay, ICU mortality and hospital mortality were also recorded.

\section{Serum lactate and severity variables}

The highest serum lactate levels were recorded on D0 and D1 and the serum lactate difference was calculated (lactate D0 - lactate D1). Severity was assessed from the ICU mortality and SAPS II score. Severe patients were considered "more severe" or "less severe" if their SAPS II score was $\geq$ or $<$ the median SAPS II score of the population respectively.

\section{STATISTICAL ANALYSIS}

Data are described as median with interquartile range (IQR) for continuous variables and as number and percentage for categorical data. Patient characteristics were first compared between groups (AMI vs Control) using the Wilcoxon signed rank test or McNemar's Chi-squared test. There were few missing data (1 for lactate level at D0, 16 for lactate level at D1 and 39 for catecholamines). We performed sensitivity analyses using multiple imputations by chained equations. Lactate levels between groups were compared using the generalized estimating equations (GEE) model with a gamma distribution. Goodness 
of fit for gamma distribution was assessed using histograms and quantiles' plots. The dependency between paired observations was taken into account using an "exchangeable" correlation matrix. A Gaussian distribution was used for the comparison of lactate differences. Results are presented as mean differences with their $95 \%$ confidence intervals. Confidence intervals for gamma models were calculated with the delta method $[19,20]$. A receiver operating characteristics (ROC) analysis was performed to investigate the performance of serum lactate levels at D0/D1 and serum lactate difference to predict severity and hospital mortality. Areas under the curve (AUCs) are presented with their $95 \%$ confidence intervals ( $95 \% \mathrm{Cls})$. AUCs between paired ROC curves were compared using the bootstrap resampling method with 10,000 replicates. A p-value $<0.05$ was considered as statistically significant. All the analyses were performed using R software version 3.6.0. R Core Team (2019). R: A language and environment for statistical computing. R Foundation for Statistical Computing, Vienna, Austria. URL https://www.R-project.org/.

\section{Results}

\section{Baseline characteristics of the patients}

The four centers enrolled 214 patients in the MIICU cohort. We excluded patients when AMI was diagnosed more than $24 \mathrm{~h}$ after ICU admission and matched controls were not found for four patients. Finally, we included 137 AMI patients matched with 137 control patients (Fig. 1).

Median age was $73[62 ; 80]$ years, male-to-female ratio was 168/106 (61\% / 39\%) and median SAPS II was 56 [45; 70] (Table 1). There was no significant difference between groups in terms of age, male-tofemale ratio and SAPS II (matching parameters). More patients had a history of peripheral arterial disease in the AMI group than in the control group $(46.0 \%$ vs. $23.4 \%, p<0.001)$. Urgent surgery was the first cause of ICU admission in both groups but more urgent surgical admissions were reported in the AMI group than in the control group $(82.5 \%$ vs. $62.5 \%, p<0.001)$ (Table 1). At D0 in both groups, more than a quarter of the patients were treated with catecholamines, which was still infused at D1 for almost $80 \%$ of the entire cohort. There was significantly more liver failure in the AMI group than in the control group ( $45.6 \%$ vs. $31.4 \%, p=0.006$ ) (Table 1 ). The ICU mortality was $38 \%$ in the AMI group and $30 \%$ in the control group $(p=0.145)($ Table 1$)$.

\section{Serum lactate values at D0, D1 and lactate difference}

Serum lactate levels were increased in both groups at D0 and D1 (Fig. 2). The mean serum lactate difference between groups (AMI-Control) was $0.5[-0.4 ; 1.4] \mathrm{mmol} / \mathrm{L}$ at $\mathrm{D} 0$ and $0.5[-0.4 ; 1.3] \mathrm{mmol} / \mathrm{L}$ at D1 $(p=0.284$ and $p=0.278$ respectively). Mean serum lactate difference (D1-D0) was $0.7[-12.0 ; 9.2] \mathrm{mmol} / \mathrm{L}$ in the control group and $0.5[-12.2 ; 9.5] \mathrm{mmol} / \mathrm{L}$ in AMI group and these values were not statistically different $(p=0.547)$.

\section{Serum lactate as diagnostic marker of AMI}


The performance of serum lactate as a diagnostic marker of AMI was poor (Table 2). At D0 and D1, the thresholds were $2.0 \mathrm{mmol} / \mathrm{L}$ and $2.3 \mathrm{mmol} / \mathrm{L}$ with AUCs of ROC curves at 0.57 [0.51; 0.63] and 0.59 [0.53; $0.57]$.

\section{Serum lactate as a specific marker of severity}

At DO in the AMI group, a serum lactate level above $4.0 \mathrm{mmol} / \mathrm{L}$ predicted ICU mortality with a sensitivity of 0.71 , specificity of 0.71 and AUC of 0.74 [0.65; 0.82] (Table 3, Fig. 3). At D1 in the AMI group, a serum lactate level above $5.1 \mathrm{mmol} / \mathrm{L}$ predicted ICU mortality with a sensitivity of 0.64 , specificity of 0.87 and AUC of 0.76 [0.66;0.87]. The difference in serum lactate levels (D0-D1) was less predictive of ICU mortality and there was no significant difference between groups (Table 3). Serum lactate levels (D0, D1 and D0D1) were also relatively good predictors of a high SAPS II score $(\geq 56)$ and we observed no significant differences between groups (Table 3, Fig. 4).

\section{Discussion}

In our study, no association was found between serum lactate levels and AMI diagnosis. To our knowledge, our study is the first to compare the prognostic value of serum lactate on ICU mortality between AMI and control patients.

In a previous study, serum lactate was associated with the diagnosis of AMI [7]. As the increase in serum lactate was initially thought to be due to intestinal cell hypoxia, serum lactate was considered to be the best diagnostic biomarker of AMI [21]. However, several experimental studies suggested that AMI was not systematically associated with increased serum lactate $[22,23]$. Furthermore, lactate metabolism is complex. In critical situations, such as in severe AMI, the increase in serum lactate may include 1) an intestinal hypoxic component, 2) a component related to the systemic inflammatory response and its associated hypermetabolism and 3) a component related to decreased hepatic metabolism [24, 25]. Finally, severe AMI may itself be associated with septic complications (digestive perforation, peritonitis) and hemodynamic events, which may themselves be associated with elevated serum lactate.

In 2012, Demir et al. reviewed seven clinical studies testing serum lactate as a diagnostic tool for AMI [7]. T he sensitivity of lactate as a diagnostic marker of AMI in these studies ranged from 33-78\% for a specificity ranging from 36-72\%. Other studies confirmed that lactate is not a diagnostic marker of AMI $[6,8,26,27]$. The ESVS and the ESTES therefore recommended that serum lactate is not used to diagnose or rule out AMI $[2,3]$. In the largest published cohort of 780 AMI patients, $23 \%$ had normal serum lactate levels at the time of AMI diagnosis [5], confirming the danger of not making this diagnosis when there is no increase in serum lactate. Unfortunately, serum lactate is still widely used [9] and the diagnosis of AMI may still be delayed when serum lactate is normal, leading to delayed management and a loss of opportunity for patients [10]. To date, neither serum lactate nor any other biomarker has been shown to be useful in the diagnosis of AMI [2,3]. 
In our study, the cohort included only ICU patients with a median SAPS II score of 56 (predicted mortality $59.8 \%$ ) and an ICU mortality of about $40 \%$. There was no significant difference in serum lactate between the two groups. This lack of significant difference between the two groups translates into poor performance of serum lactate to diagnose AMI. Our study therefore confirms the studies showing that lactatemia is a poor diagnostic tool in AMI [7]. As a result, a normal lactatemia should not rule out the diagnosis of AMI [2]. In other words, we observed no specific association between serum lactate and AMI diagnosis.

Increased serum lactate predicted ICU mortality in both groups suggesting that there is no specific association between serum lactate and AMI prognosis. In a recent single-center retrospective study including $221 \mathrm{AMI}$ patients, Sindall et al. observed that an increase of each $\mathrm{mmol} / \mathrm{L}$ of lactate above the mean $(3.04 \mathrm{mmol} / \mathrm{L})$ was associated with an odds ratio for mortality of $1.36[1.10 ; 1.66]$ [28]. In a singlecenter retrospective study including 214 patients, Caluwaerts et al. showed that maximum vasopressor dose, change in lactate during the first 24 hours in the ICU and anticoagulation were the three predictors of mortality in AMI [11]. The AMI mortality reported by the authors of this study was close to our ICU mortality. Moreover, the ability of serum lactate at D0 to predict mortality was also in line with their findings (AUC ROC curve of 0.72 [0.64-0.80] vs. $0.74[0.65 ; 0.82]$ ). However, we did not observe the same results for D1 serum lactate levels and the difference between D0-D1. Indeed, they found that the difference D0-D1 was the best predictor of mortality (AUC 0.89 [0.84-0.94]) whereas we reported a low AUC $(0.59$ [0.47; 0.71]). In our study, we did not include patients with AMI diagnosed after ICU admission. This probably led to the selection of more cases of AMI with a vascular cause. Indeed, non-occlusive mesenteric ischemia (NOMI) often occurs during the ICU stay and not at ICU admission. NOMI is typically associated with a form of circulatory failure with low cardiac output. Although NOMI is considered to be more severe than AMI with a vascular cause [29], correction of low cardiac output may normalize serum lactate and improve digestive circulation [30]. In this situation, a decrease in serum lactate probably reflects the overall improvement of the patient rather than specifically the perfusion of the bowel.

Our results confirm that serum lactate is indeed predictive of mortality in AMI but also shows that this is not specific to AMI.

Even if serum lactate is not a specific marker of AMI prognosis, once AMI is diagnosed, serum lactate can be useful for patient management. Nuzzo et al. found in 67 patients that lactate was one of the three factors predicting irreversible AMI called irreversible transmural intestinal necrosis and could therefore be used to decide on surgical intervention [12]. However, in this study the predictive threshold for irreversible transmural intestinal necrosis was $2 \mathrm{mmol} / \mathrm{L}$, which can be considered a low serum lactate level.

Furthermore, the model was accurately predictive of irreversible transmural intestinal necrosis when at least two risk factors were present. Thus, if hyperlactatemia was the only risk factor, AMI was irreversible in only $38 \%$ of cases. Emile et al. did not find that serum lactate was predictive of intestinal necrosis in a cohort of 101 patients including a majority with venous thrombosis [31]. Hyperlactatemia may be more indicative of systemic hemodynamic impairment or multiorgan failure than specific bowel failure. Ambe et al. did not find a relation between intraoperative serum lactate and the extent of intestinal necrosis but 
the group of patients with the highest serum lactate were those with multiorgan failure [32]. Serum lactate is therefore a marker of severity, signifying the presence of systemic complications in a population of AMI patients [33].

This multicenter and matched study has several limitations. As data were collected retrospectively, the causes of death were not determined. Specifically, we did not collect data on the "do not resuscitate" orders, which were probably frequent in this population. The type of AMI was poorly reported, although this feature may be of interest in terms of outcomes. Specifically, we did not distinguish AMI due to arterial or venous occlusions and NOMI as clear guidelines defining NOMI were not available at the time of data collection, [2]. We did not collect data on several confounding factors such as history of hypertension, stroke, and coronary artery disease and our data cannot discriminate if atrial fibrillation was an acute event or a chronic disease. We did not collect on other relevant variables such as blood pressure or duration of hypotension although they are included to some degree in the SOFA score. Finally, we did not determine the delay between AMI diagnosis and surgery although this delay is probably one of the critical endpoints in patients with AMI as it was reported elsewhere as an independent risk factor of death $[6,34]$.

\section{Conclusions}

No specific link was observed between serum lactate levels and the diagnosis or outcome of AMI. There is still no useful diagnostic biomarker for AMI and normal serum lactate does not rule out this diagnosis. Once AMI has been diagnosed, serum lactate may be used to assess the overall severity of the patient and tailor its management.

\section{Declarations}

\section{- Ethics approval and consent to participate}

The study was approved by the Ethics Committee of the French Society of Anesthesia and Intensive Care (IRB CERAR-00010254 -2016-070) in accordance with French regulations.

\section{- Consent for publication}

Not applicable, in accordance with French regulations.

\section{- Availability of data and material}

All data generated or analysed during this study are included in this published article.

\section{- Competing interests}

The authors declare no financial or non-financial competing interest. 


\section{- Funding}

No source of funding.

\section{- Authors' contributions}

OC, MLo, FS, conceived and designed the analysis, performed the analysis and wrote the paper, MLe and PMM conceived and designed the analysis, contributed to the analysis, and wrote the paper, MLo, AL, PP, $A O, A D, T R, T G, D A, P A, N C, C T, W O$, and LZ collected the data, contributed to data analysis and provided critical feedback for manuscript writing.

\section{- Acknowledgements}

Not applicable

\section{References}

1. Karkkainen JM, Lehtimaki TT, Manninen H, Paajanen H. Acute Mesenteric Ischemia Is a More Common Cause than Expected of Acute Abdomen in the Elderly. J Gastrointest Surg. 2015;19(8):1407-14.

2. Tilsed JV, Casamassima A, Kurihara H, Mariani D, Martinez I, Pereira J, Ponchietti L, Shamiyeh A, AlAyoubi F, Barco LA, et al. ESTES guidelines: acute mesenteric ischaemia. European journal of trauma emergency surgery: official publication of the European Trauma Society. 2016;42(2):253-70.

3. Bjorck M, Koelemay M, Acosta S, Bastos Goncalves F, Kolbel T, Kolkman JJ, Lees T, Lefevre JH, Menyhei G, Oderich G, et al. Management of the Diseases of Mesenteric Arteries and Veins: Clinical Practice Guidelines of the European Society of Vascular Surgery (ESVS). Eur J Vasc Endovasc Surg. 2017;53(4):460-510.

4. Carver TW, Vora RS, Taneja A. Mesenteric Ischemia. Crit Care Clin. 2016;32(2):155-71.

5. Leone M, Bechis C, Baumstarck K, Ouattara A, Collange O, Augustin P, Annane D, Arbelot C, Asehnoune K, Baldesi O, et al. Outcome of acute mesenteric ischemia in the intensive care unit: a retrospective, multicenter study of 780 cases. Intensive Care Med. 2015;41(4):667-76.

6. Cudnik MT, Darbha S, Jones J, Macedo J, Stockton SW, Hiestand BC. The diagnosis of acute mesenteric ischemia: A systematic review and meta-analysis. Academic emergency medicine: official journal of the Society for Academic Emergency Medicine. 2013;20(11):1087-100.

7. Demir IE, Ceyhan GO, Friess H. Beyond lactate: is there a role for serum lactate measurement in diagnosing acute mesenteric ischemia? Dig Surg. 2012;29(3):226-35.

8. Derikx JP, Schellekens DH, Acosta S. Serological markers for human intestinal ischemia: A systematic review. Best Pract Res Clin Gastroenterol. 2017;31(1):69-74. 
9. Brillantino A, lacobellis F, Renzi A, Nasti R, Saldamarco L, Grillo M, Romano L, Castriconi M, Cittadini $\mathrm{A}$, De Palma $\mathrm{M}$, et al. Diagnostic value of arterial blood gas lactate concentration in the different forms of mesenteric ischemia. European journal of trauma emergency surgery: official publication of the European Trauma Society. 2018;44(2):265-72.

10. Taylor J, Mandzhieva B, Shobar R. Diagnosis of Acute Mesenteric Ischemia in a Patient with EndStage Renal Disease with Normal Serum Lactate. Cureus. 2020;12(1):e6708.

11. Caluwaerts $M$, Castanares-Zapatero $D$, Laterre PF, Hantson P. Prognostic factors of acute mesenteric ischemia in ICU patients. BMC Gastroenterol. 2019;19(1):80.

12. Nuzzo A, Maggiori L, Ronot M, Becq A, Plessier A, Gault N, Joly F, Castier Y, Vilgrain V, Paugam C, et al: Predictive Factors of Intestinal Necrosis in Acute Mesenteric Ischemia: Prospective Study from an Intestinal Stroke Center. Am J Gastroenterol 2017.

13. Leone M, Constantin JM, Dahyot-Fizelier C, Duracher-Gout C, Joannes-Boyau O, Langeron O, Legrand $M$, Mahjoub Y, Mirek S, Mrozek S, et al. French intensive care unit organisation. Anaesthesia critical care pain medicine. 2018;37(6):625-7.

14. Toulouse E, Masseguin C, Lafont B, McGurk G, Harbonn A, Granier JAR, Dupeyron S, Bazin A. JE: French legal approach to clinical research. Anaesth Crit Care Pain Med. 2018;37(6):607-14.

15. Allyn J, Ferdynus C, Bohrer M, Dalban C, Valance D, Allou N. Simplified Acute Physiology Score II as Predictor of Mortality in Intensive Care Units: A Decision Curve Analysis. PLoS One. 2016;11(10):e0164828.

16. Le Gall JR, Lemeshow S, Saulnier F. A new Simplified Acute Physiology Score (SAPS II) based on a European/North American multicenter study. JAMA. 1993;270(24):2957-63.

17. Atramont A, Lindecker-Cournil V, Rudant J, Tajahmady A, Drewniak N, Fouard A, Singer M, Leone M, Legrand M. Association of age with short-term and long-term mortality among patients discharged from intensive care units in France. JAMA Network Open Critical Care Medicine. 2019;2(5):e193215. in press.

18. Peres Bota D, Melot C, Lopes Ferreira F, Nguyen Ba V, Vincent JL. The Multiple Organ Dysfunction Score (MODS) versus the Sequential Organ Failure Assessment (SOFA) score in outcome prediction. Intensive Care Med. 2002;28(11):1619-24.

19. Oehlert GW. A Note on the Delta Method. The American Statistician. 1992;46(1):27-9.

20. Mandel M. Simulation-Based Confidence Intervals for Functions With Complicated Derivatives. The American Statistician. 2013;67(2):76-81.

21. Lange $H$, Jackel R. Usefulness of plasma lactate concentration in the diagnosis of acute abdominal disease. Eur J Surg. 1994;160(6-7):381-4.

22. Acosta S, Nilsson TK, Malina J, Malina M. L-lactate after embolization of the superior mesenteric artery. J Surg Res. 2007;143(2):320-8.

23. Jakob SM, Merasto-Minkkinen M, Tenhunen JJ, Heino A, Alhava E, Takala J. Prevention of systemic hyperlactatemia during splanchnic ischemia. Shock. 2000;14(2):123-7. 
24. Levy B. Lactate and shock state: the metabolic view. Curr Opin Crit Care. 2006;12(4):315-21.

25. James JH, Luchette FA, McCarter FD, Fischer JE. Lactate is an unreliable indicator of tissue hypoxia in injury or sepsis. Lancet. 1999;354(9177):505-8.

26. van der Voort PH, Westra B, Wester JP, Bosman RJ, van Stijn I, Haagen IA, Loupatty FJ, Rijkenberg S. Can serum L-lactate, D-lactate, creatine kinase and I-FABP be used as diagnostic markers in critically ill patients suspected for bowel ischemia. BMC Anesthesiol. 2014;14:111.

27. Matsumoto S, Sekine K, Funaoka H, Yamazaki M, Shimizu M, Hayashida K, Kitano M. Diagnostic performance of plasma biomarkers in patients with acute intestinal ischaemia. Br J Surg. 2014;101(3):232-8.

28. Sindall ME, Davenport DL, Wallace P, Bernard AC. Validation of the American Association for the Surgery of Trauma grading system for acute mesenteric ischemia-More than anatomic severity is needed to determine risk of mortality. J Trauma Acute Care Surg. 2020;88(5):671-6.

29. Grotelüschen R, Bergmann W, Welte MN, Reeh M, Izbicki JR, Bachmann K. What predicts the outcome in patients with intestinal ischemia? A single center experience. J Visc Surg. 2019;156(5):405-11.

30. Bakker J, Postelnicu R, Mukherjee V. Lactate: Where Are We Now? Crit Care Clin. 2020;36(1):115-24.

31. Emile SH. Predictive Factors for Intestinal Transmural Necrosis in Patients with Acute Mesenteric Ischemia. World J Surg. 2018;42(8):2364-72.

32. Ambe PC, Kang K, Papadakis M, Zirngibl H. Can the Preoperative Serum Lactate Level Predict the Extent of Bowel Ischemia in Patients Presenting to the Emergency Department with Acute Mesenteric Ischemia? Biomed Res Int. 2017;2017:8038796.

33. Jansen TC, van Bommel J, Woodward R, Mulder PG, Bakker J. Association between blood lactate levels, Sequential Organ Failure Assessment subscores, and 28-day mortality during early and late intensive care unit stay: a retrospective observational study. Crit Care Med. 2009;37(8):2369-74.

34. Acosta S, Bjorck M. Modern treatment of acute mesenteric ischaemia. Br J Surg. 2014;101(1):e1008.

\section{Tables}

Table 1. Baseline characteristics of patients 


\begin{tabular}{|c|c|c|c|c|}
\hline & All $(n=274)$ & CTR $(n=137)$ & AMI $(n=137)$ & $\mathrm{p}$ \\
\hline Age * (years) - median, [IQR] & $73[62,80]$ & $73[63,80]$ & $73[62,81]$ & 0.810 \\
\hline Male-to-female ratio * $\mathrm{n}(\%)$ & $\begin{array}{l}168 / 106 \\
(61 / 39)\end{array}$ & $\begin{array}{l}85 / 52 \\
(62.0 / 48.0)\end{array}$ & $\begin{array}{l}83 / 54 \\
(60.6 / 49.4)\end{array}$ & 0.593 \\
\hline SAPS II * - median, [IQR] & $56[45,70]$ & $56[45,71]$ & $56[45,68]$ & 0.343 \\
\hline Atrial fibrillation, n (\%) & $81(29.6)$ & $42(30.1)$ & $39(28.5)$ & 0.686 \\
\hline Peripheral arterial disease, $\mathrm{n}(\%)$ & $95(34.7)$ & $32(23.4)$ & $63(46.0)$ & $<0.001$ \\
\hline Cancer history, n (\%) & $77(28.1)$ & $45(32.8)$ & $32(23.4)$ & 0.085 \\
\hline \multicolumn{5}{|l|}{ Admission type } \\
\hline \multirow{3}{*}{$\begin{array}{l}\text { - Medical, n (\%) } \\
\text { - Surgical, non-urgent, n (\%) } \\
\text { - Surgical, urgent, n (\%) }\end{array}$} & $35(12.8)$ & $25(18.4)$ & $10(7.3)$ & \multirow{3}{*}{$\dot{0} 001$} \\
\hline & $37(13.5)$ & $25(18.4)$ & $12(8.8)$ & \\
\hline & $198(72.5)$ & $85(62.5)$ & $113(82.5)$ & \\
\hline Catecholamines D0, n (\%) & $66(28.1)$ & $28(28.6)$ & $38(27.7)$ & 1 \\
\hline \multirow{3}{*}{$\begin{array}{l}\text { - Norepinephrine, } \mathrm{n}(\%) \\
\text { - Epinephrine, } \mathrm{n}(\%) \\
\text { - Dobutamine, } \mathrm{n}(\%)\end{array}$} & $60(27.9)$ & $25(25.5)$ & $35(29.9)$ & 0.841 \\
\hline & $8(3.7)$ & $2(2.0)$ & $6(5.1)$ & 0.375 \\
\hline & $7(3.3)$ & $2(2.0)$ & $5(4.7)$ & 1 \\
\hline Catecholamines D1, n (\%) & $215(79.0)$ & $110(80.9)$ & $105(77.2)$ & 0.435 \\
\hline \multirow{3}{*}{$\begin{array}{l}\text { - Norepinephrine, n (\%) } \\
\text { - Epinephrine, n (\%) } \\
\text { - Dobutamine, n (\%) }\end{array}$} & $201(73.9)$ & $98(72.1)$ & $103(75.7)$ & 0.386 \\
\hline & $27(9.9)$ & $16(8.1)$ & $11(11.8)$ & 0.394 \\
\hline & $46(16.9)$ & $22(17.6)$ & $24(16.2)$ & 0.739 \\
\hline Need for RTT, n (\%) & $89(32.5)$ & $45(32.8)$ & $44(32.1)$ & 0.881 \\
\hline $\begin{array}{l}\text { Platelet count (giga/L) - median, } \\
\text { [IQR] }\end{array}$ & $176[110,272]$ & $176[105,270]$ & $175[119,273]$ & 0.483 \\
\hline Liver failure, n (\%) & $104(38.5)$ & $42(31.4)$ & $62(45.6)$ & 0.006 \\
\hline SOFA score (D0) - median, [IQR] & $9[7,12]$ & $9[6,12]$ & $10[7,12]$ & 0.826 \\
\hline Need for MV, n (\%) & $259(94.5)$ & $132(96.3)$ & $127(92.7)$ & 0.302 \\
\hline MV (days) - median, [IQR] & $3.0[1.0,6.7]$ & $3.0[1.0,7.0]$ & $3.0[1.0,6.0]$ & 0.242 \\
\hline ICU LOS (days) - median, [IQR] & $6.0[2.0,12.0]$ & $6.0[3.0,12.7]$ & $6.0[2.0,11.5]$ & 0.278 \\
\hline ICU mortality, n (\%) & $93(33.9)$ & $41(29.9)$ & $52(38.0)$ & 0.145 \\
\hline
\end{tabular}

AMI = Acute Mesenteric Ischemia group, CTR: control group 
Quantitative data are expressed as median [IQR], IQR = interquartile range, qualitative data are expressed as numbers $(\%)$

SAPS II: Simplified acute physiologic score, D0: 0-24h, D1: 24-48h after ICU admission, RRT: renal replacement therapy, SOFA: Sequential organ failure assessment, MV: mechanical ventilation, ICU: intensive care unit, LOS: length of stay.

* Patients were matched on SAPS II score, age, gender and centre of inclusion

Table 2. Performance indicators of serum lactate for AMI diagnosis

$\begin{array}{llll}\text { Parameter } & \text { Lactate D0 } & \text { Lactate D1 } & \text { D0-D1 } \\ \text { Threshold } & \geq 2.0 \mathrm{mmol} & \geq 2.3 \mathrm{mmol} / \mathrm{L} & \geq 2.1 \mathrm{mmol} / \mathrm{L}\end{array}$

\begin{tabular}{llll} 
Sensitivity $[95 \% \mathrm{Cl}]$ & $0.72[0.64,0.80]$ & $0.51[0.41,0.60]$ & $0.24[0.16,0.32]$ \\
\hline Specificity $[95 \% \mathrm{Cl}]$ & $0.43[0.34,0.51]$ & $0.67[0.58,0.75]$ & $0.82[0.74,0.88]$ \\
\hline Positive likelihood ratio $[95 \% \mathrm{Cl}]$ & $1.26[1.05,1.51]$ & $1.53[1.13,2.07]$ & $1.32[0.80,2.16]$ \\
\hline Negative likelihood ratio $[95 \% \mathrm{Cl}]$ & $0.65[0.47,0.91]$ & $0.74[0.59,0.92]$ & $0.93[0.82,1.06]$ \\
\hline Diagnostic odds ratio $[95 \% \mathrm{Cl}]$ & $1.94[1.17,3.21]$ & $2.07[1.23,3.48]$ & $1.42[0.76,2.65]$ \\
\hline Positive predictive value $[95 \% \mathrm{Cl}]$ & $0.56[0.48,0.63]$ & $0.57[0.47,0.67]$ & $0.54[0.39,0.68]$ \\
\hline Negative predictive value $[95 \% \mathrm{Cl}]$ & $0.60[0.50,0.70]$ & $0.61[0.52,0.69]$ & $0.55[0.47,0.62]$ \\
\hline Accuracy $[95 \% \mathrm{Cl}]$ & $0.58[0.51,0.63]$ & $0.59[0.53,0.66]$ & $0.55[0.48,0.61]$ \\
\hline AUC ROC $[95 \% \mathrm{Cl}]$ & $0.57[0.51,0.64]$ & $0.59[0.53,0.57]$ & $0.51[0.44,0.52]$
\end{tabular}

AMI : acute mesenteric ischemia, D0: 0-24h, D1: 24-48h after intensive care unit admission

[95\% Cl]: 95\% confidence interval

Positive values $(\mathrm{P})$ : lactate $\mathrm{D} 0>2.0 \mathrm{mmol} / \mathrm{L}$ or lactate $\mathrm{D} 1>2.3 \mathrm{mmol} / \mathrm{L}$

Negative values $(\mathrm{N})$ : lactate $\mathrm{D} 0 \leq 2.0 \mathrm{mmol} / \mathrm{L}$ or lactate $\mathrm{D} 1 \leq 2.3 \mathrm{mmol} / \mathrm{L}$

True positive values (TP): lactate D0 $>2.0 \mathrm{mmol}$ or lactate $\mathrm{D} 1>2.3 \mathrm{mmol} / \mathrm{L}$ when $\mathrm{AMl}+$

True negative values $(\mathrm{TN})$ : lactate $\mathrm{D} 0 \leq 2.0 \mathrm{mmol} / \mathrm{L}$ or lactate $\mathrm{D} 1 \leq 2.3 \mathrm{mmol} / \mathrm{L}$ when $\mathrm{AMI}$ -

False positive values (FP): lactate D0 $>2.0 \mathrm{mmol}$ or lactate D1 $>2.3 \mathrm{mmol} / \mathrm{L}$ when AMI -

False negative values $(\mathrm{FN})$ : lactate $\mathrm{D} 0 \leq 2.0 \mathrm{mmol} / \mathrm{L}$ or lactate $\mathrm{D} 1 \leq 2.3 \mathrm{mmol} / \mathrm{L}$ when $\mathrm{AMI}+$ 
Sensitivity: TP/P, Specificity: TN/N

Positive likelihood ratio (LR+): sensitivity/(1-specificity), Negative likelihood ratio (LR-): (1sensitivity)/specificity

Diagnostic odds ratio: $L R(+) / L R(-)$

Positive predictive value: TP/(P+N), Negative predictive value: $T N /(P+N)$

Accuracy, proportion of correctly identified subjects: $(T P+T N) /(P+N)$

AUC ROC: area under the curve of the receiver operating characteristics curve

Table 3. Serum lactate as markers of severity 


\begin{tabular}{|c|c|c|c|c|}
\hline & All $(n=274)$ & CTR $(n=137)$ & AMI $(n=137)$ & $\mathrm{p}$ \\
\hline \multicolumn{5}{|l|}{ Lactate DO } \\
\hline \multicolumn{5}{|l|}{ ICU mortality } \\
\hline Threshold (mmol/L) & 4.0 & 5.2 & 4.0 & \\
\hline AUC $[95 \% \mathrm{Cl}]$ & $0.72[0.65,0.78]$ & $0.69[0.59,0.79]$ & $0.74[0.65,0.82]$ & 0.513 \\
\hline \multicolumn{5}{|l|}{ SAPS $\|>56$} \\
\hline Threshold (mmol/L) & 3.8 & 3.8 & 5.1 & \\
\hline AUC $[95 \% \mathrm{Cl}]$ & $0.64[0.57,0.70]$ & $0.63[0.53,0.72]$ & $0.66[0.57,0.75]$ & 0.637 \\
\hline \multicolumn{5}{|l|}{ Lactate D1 } \\
\hline \multicolumn{5}{|l|}{ ICU mortality } \\
\hline Threshold (mmol/L) & 3.9 & 2.1 & 3.9 & \\
\hline AUC [95\% Cl] & $0.75[0.67,0.82]$ & $0.74[0.64,0.84]$ & $0.76[0.66,0.87]$ & 0.772 \\
\hline \multicolumn{5}{|l|}{ SAPS $\|>56$} \\
\hline Threshold (mmol/L) & 1.9 & 2.9 & 1.9 & \\
\hline AUC [95\% Cl] & $0.68[0.62,0.75]$ & $0.70[0.61,0.79]$ & $0.67[0.58,0.78]$ & 0.743 \\
\hline \multicolumn{5}{|l|}{ Lactate D0-D1 } \\
\hline \multicolumn{5}{|l|}{ ICU Mortality } \\
\hline Threshold (mmol/L) & -0.9 & -0.9 & -1.6 & \\
\hline AUC $[95 \% \mathrm{Cl}]$ & $0.59[0.51,0.68]$ & $0.60[0.48,0.71]$ & $0.59[0.47,0.71]$ & 0.924 \\
\hline \multicolumn{5}{|l|}{ SAPS $\|>56$} \\
\hline Threshold (mmol/L) & -0.18 & -0.36 & -0.17 & \\
\hline AUC [95\% Cl] & $0.58[0.51,0.65]$ & $0.57[0.47,0.67]$ & $0.59[0.48,0.69]$ & 0.802 \\
\hline
\end{tabular}

AUC: area under the curve of the receiver operating characteristics curve, 95\% Cl: $95 \%$ confidence interval $\mathrm{AMI}=$ Acute mesenteric ischemia group, CTR: control group, D0: 0-24h, D1: 24-48h after ICU admission, ICU: intensive care unit, lactate D0-D1: lactate D0-lactate D1, SAPS II: Simplified acute physiologic score, 56 was the median of SAPS II of the entire cohort.

\section{Figures}



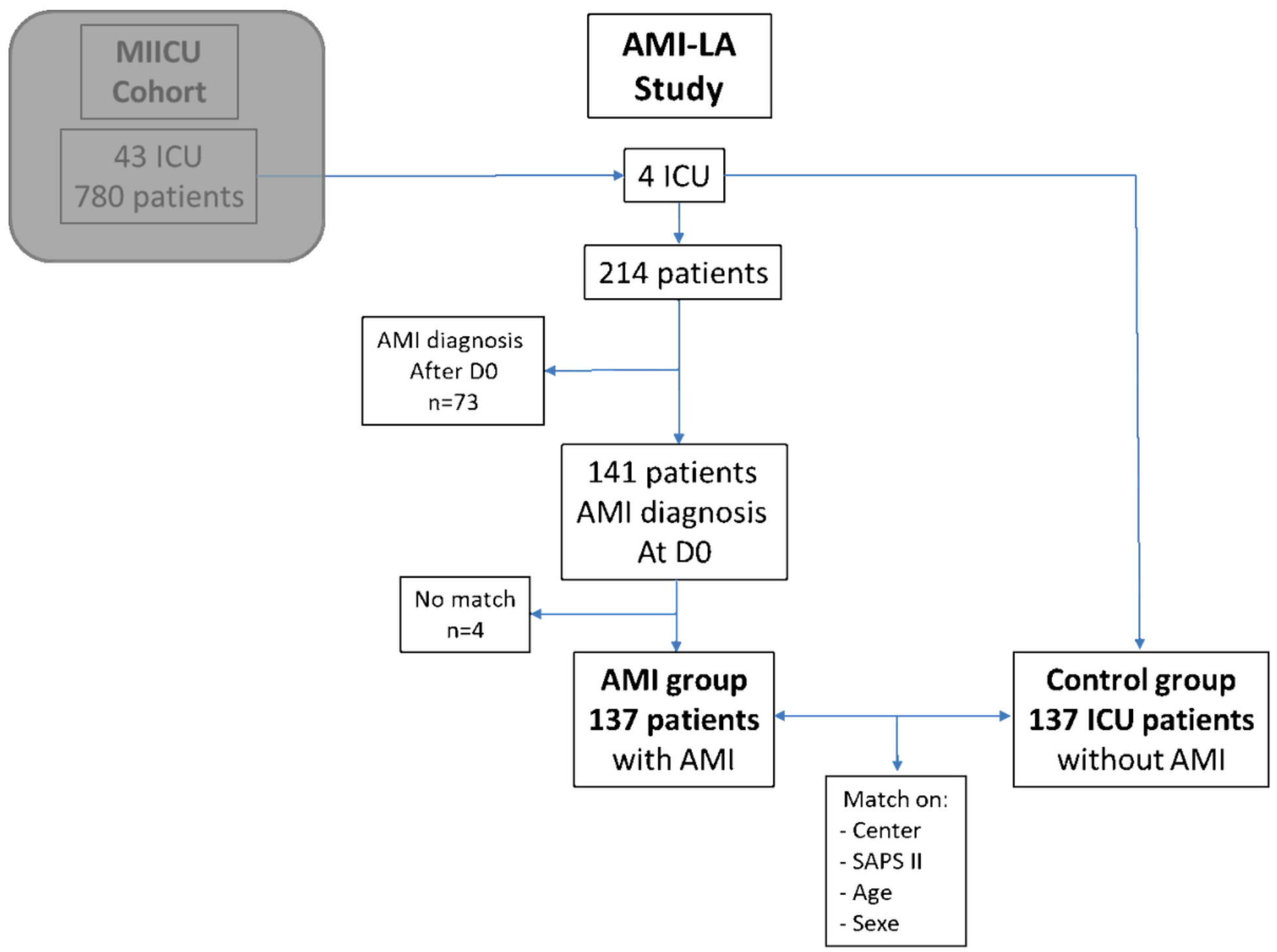

Figure 1

Fow Chart MIICU: Mesenteric ischemia in ICU cohort (43 ICUs, 780 patients with mesenteric ischemia) [5] AMI-LA: Acute Mesenteric Ischemia - Lactate, present study D0 was the first 24h after ICU admission, D1 was 24-48h after ICU admission. 


\section{Serum lactate}

CControl

पAMI

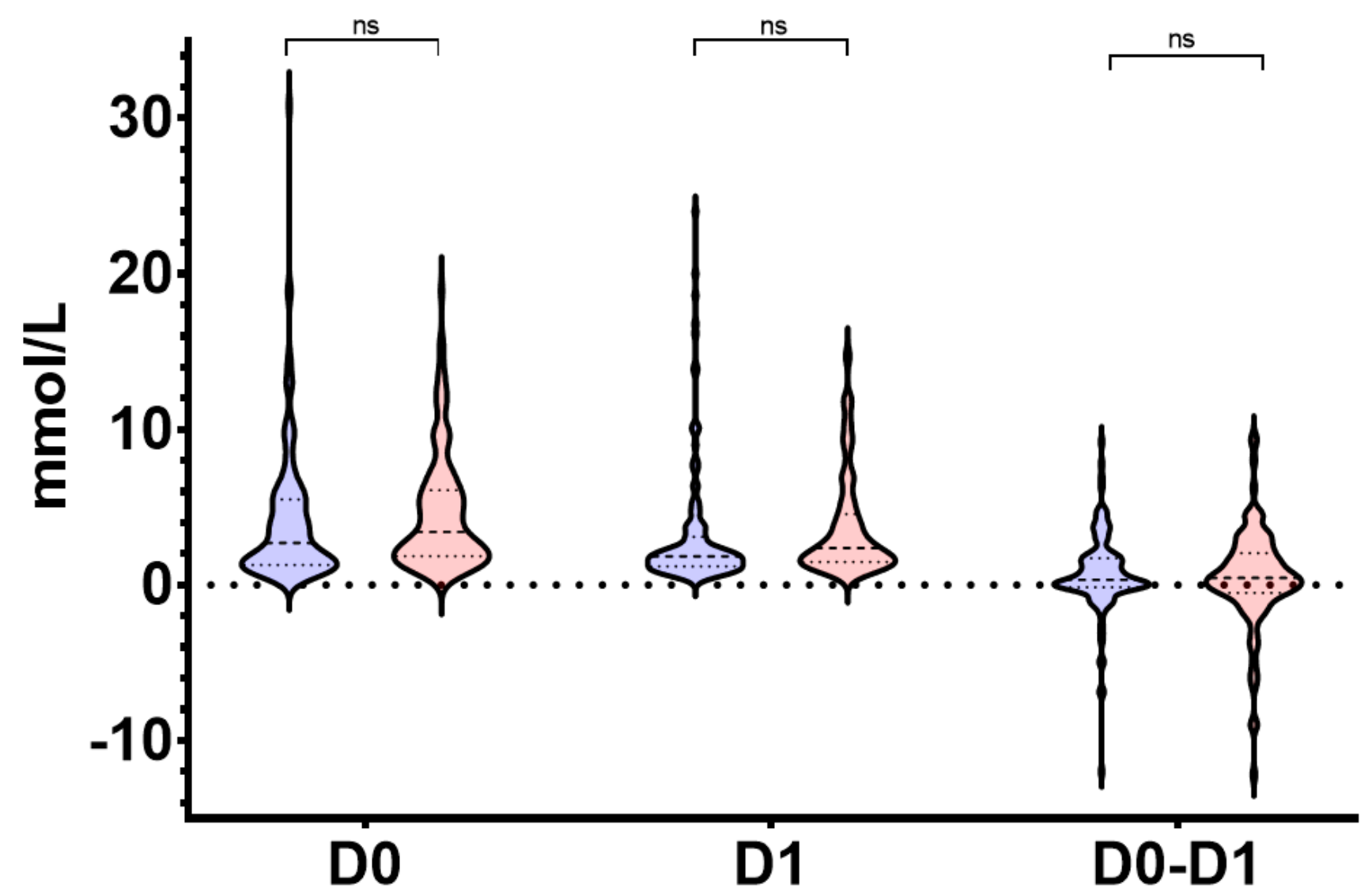

Figure 2

Serum lactate at D0, D1 and lactate difference D0 was the first 24h after ICU admission, D1 was 24-48h after ICU admission. Serum lactate difference over time was calculated as the difference between serum lactate D0 - D1. 

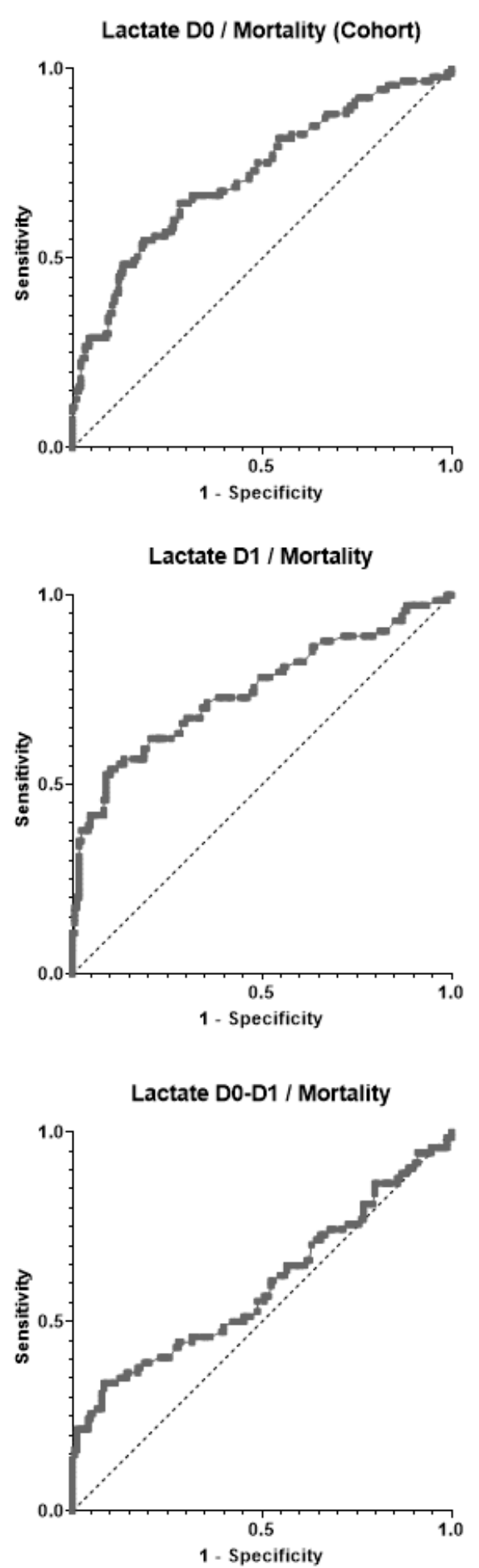

Lactate Do / Mortality CTR vs. AMI

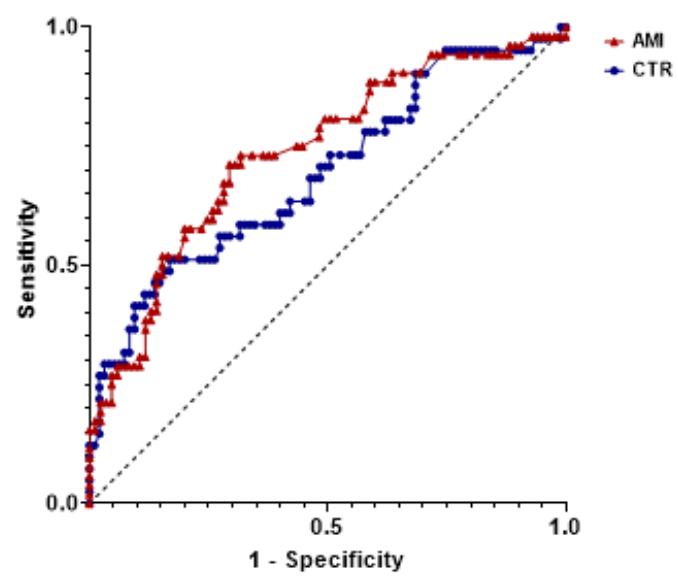

Lactate D1 / Mortality

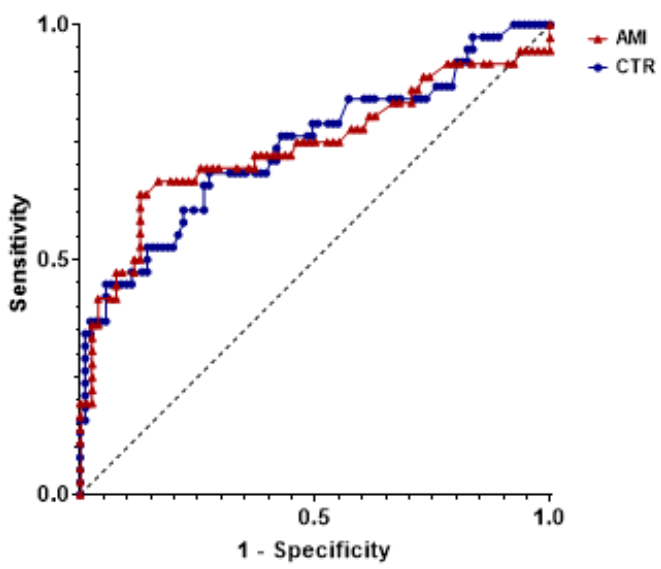

Lactate D0-D1 / Mortality

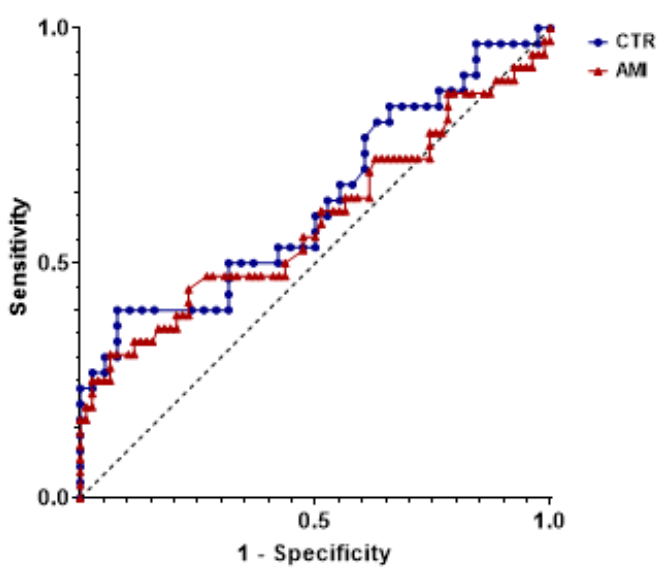

Figure 3

ROC curves testing serum lactate as marker of ICU mortality 

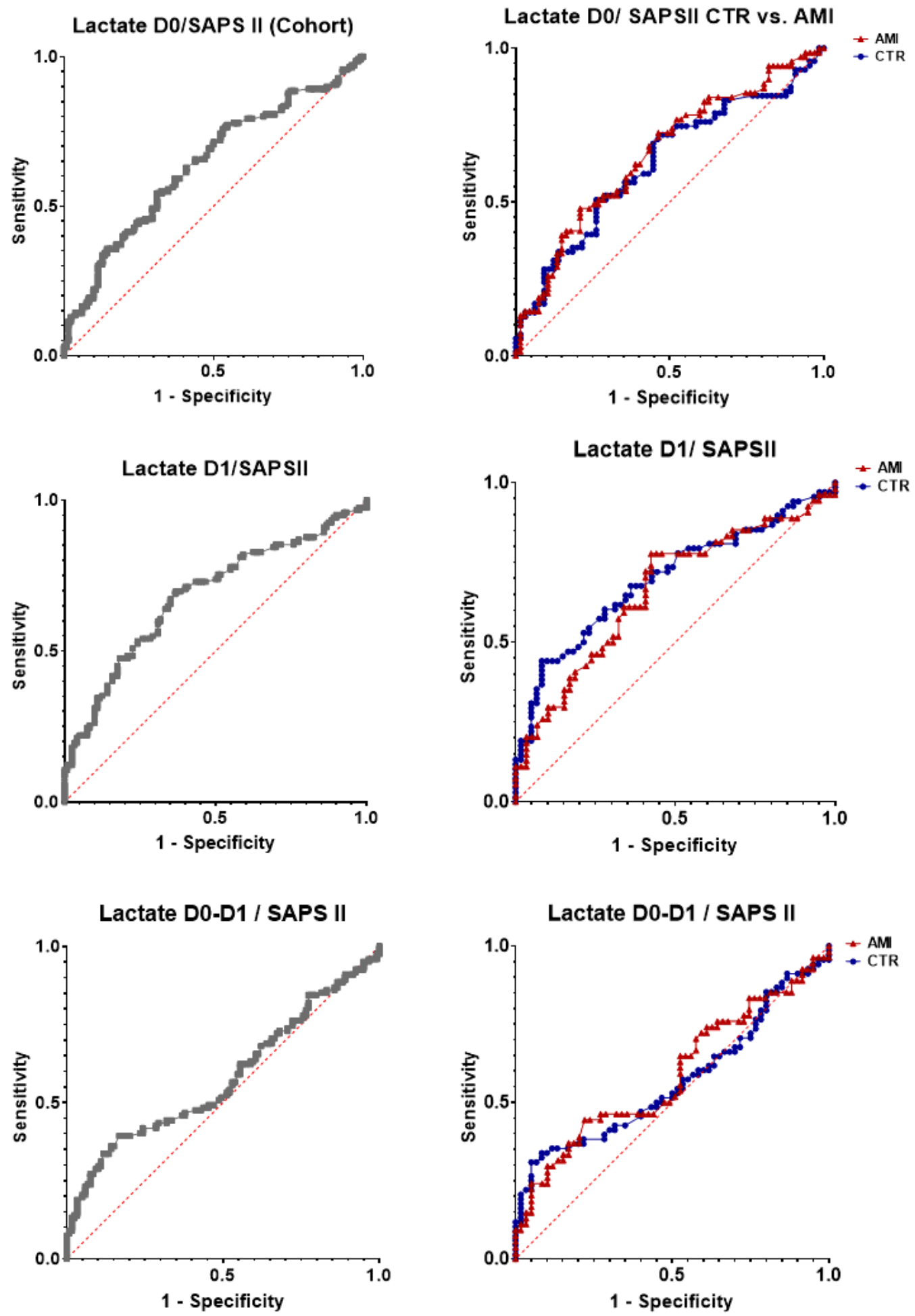

Figure 4

ROC curves testing serum lactate as marker of severity (SAPS $\| \geq 56$ ) 